\title{
Horizontal sector hemianopia of non-traumatic origin
}

\author{
R. J. S. SMITH \\ Glasgow
}

Spalding (1952) described four instances of homonymous hemianopia in which narrow sector-shaped defects occurred in the horizontal meridian, involving part of both upper and lower quadrants, and reaching to the fixation point.

These emerged from a series of 958 penetrating head injuries, mainly gunshot wounds of which i 88 had field defects attributable to injury of the optic radiations or striate cortex? and in which Spalding had precisely localized the path of the missile and the area of visua $\vec{z}$ pathway affected.

He clearly demonstrated that the unusual field picture resulted from damage to the whole horizontal thickness of the intermediate part, i.e. that lying midway between the upper and lower margins, of the optic radiation in its anterior part (Fig. I E-interrupted line).

The area in question is traversed by a line drawn head to tail through the trigone of the lateral ventricle, at which point the optic radiation forms a relatively flat plate on the lateral aspect of the trigone (Fig. I F).

If considered in relation to the skull, the area is posterior to that part of the tempora 5 lobe whereof lesions produce upper partial quadrantopia as described by Meyer (1907) and Cushing (1922), but considered functionally, as part of the visual pathway, it pre places the Meyer's loop territory. It is in both respects well in front of the posterior optic radiations (Fig. I I) where lesions can produce the familiar upper or lower quadrantopiaso as described clinically by Holmes (I918) and anatomically by Polyak (1934).

The arrangement of fibres in this area is similar to that in the adjacent external geniculate body, where the fibres subserving central vision lie above, those for peripheral vision below, and those for intermediate vision between the two.

The left visual half field is shown in Fig. I A, with central vision indicated by a stippled pattern, peripheral vision by black, and intermediate vision by white. The associated fibres in the right external geniculate body are similarly indicated (Fig. I B).

If the external geniculate body is visualized as being turned clockwise through 90 on (Fig. I C), and is thought of as consisting of malleable material which is then compressedw from side to side between the finger and thumb (Fig. I D), it becomes easier to understand? the position. The conception of continued lateral compression (Fig. I G) may be used to provide a mental picture of conditions existing in the posterior radiations (Fig. I H), where⿻ the radiation is a horseshoe-shaped structure embracing the posterior horn of the ventricle.

It is not difficult to see how a lesion involving the whole horizontal thickness of the anterior radiation (Fig. I E) will produce field defects as found in Spalding's four patients and in the patient described below. 


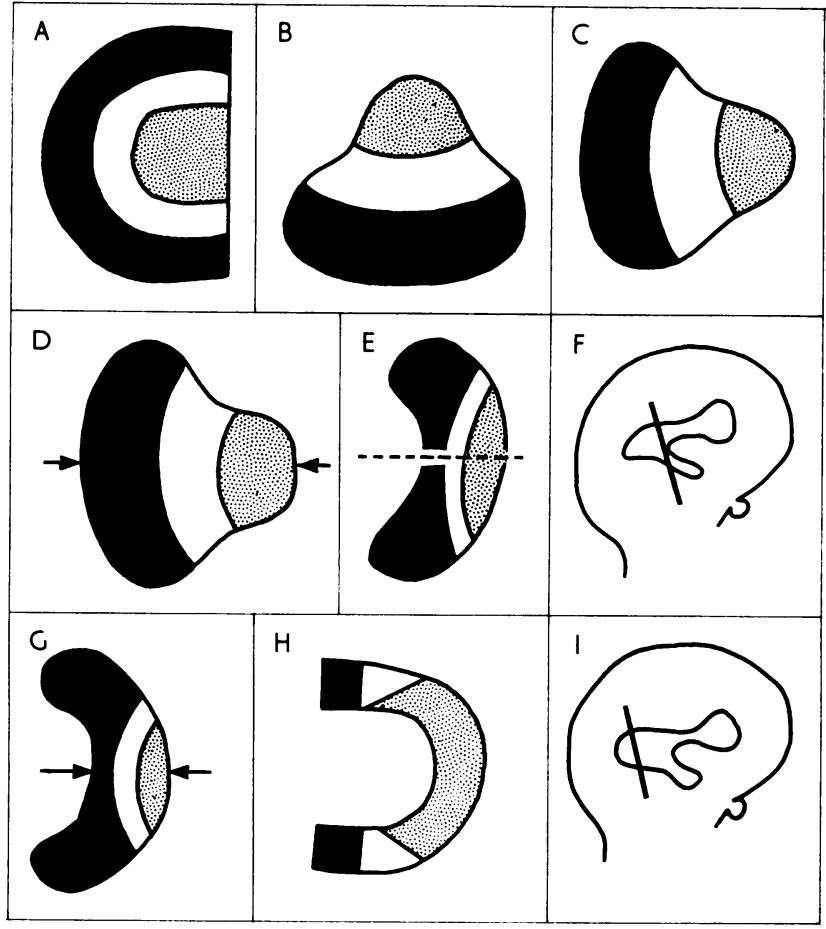

FIG. I Drawings intended to provide a simple reminder of the relevant anatomy in horizontal sector hemianopia

The subject is discussed by Scott (1957) with direct reference to Spalding's original diagrams. These illustrate in detail the distribution of the relevant visual fibres.

\section{Case report}

A hotel manager, born in 1921, became aware in March, 1959, of a sudden tingling sensation in the back of his head and neck, a roaring sound in the ears, and a peculiar taste in his mouth 'like an anaesthetic". He then lost consciousness and fell to the ground. There was no incontinence. He was unconscious for several hours. Complete recovery resulted. Simple investigations were negative.

In March, 1960, similar premonitory symptoms were experienced but passed off rapidly. There were no abnormal neurological signs. Electrocardiography, electroencephalography, and air encephalography gave negative results. Temporal lobe epilepsy was diagnosed.

In April, I 963 , the patient complained of sudden severe right-sided temporal headache and blurring of central vision. He quickly recovered and did not lose consciousness. The only neurological sign was some inco-ordination of the left arm. Bilateral carotid and vertebral angiograms were normal. Fundi and discs were normal. Central visual acuity was intact in each eye on 2 May, 1963. The central visual fields to $6 / 1000$ white, $6 / 1000$ red, and 2/1 ooo red targets were as recorded (Fig. 2).

The illness was attributed to a vascular accident involving the anterior optic radiation on the right side.

The patient returned to work some months later, and has not sought further advice. When traced on 28 January, 1969, he explained that he still has occasional "queer turns" in which he "feels faint with a taste in the mouth like chloroform", but these had not interrupted his work. He drives a car and then only is he slightly aware of his visual defect. Eye examination showed normal visual acuity, and with targets equivalent to those of 1963 visual field defects as recorded (Fig. 3). 


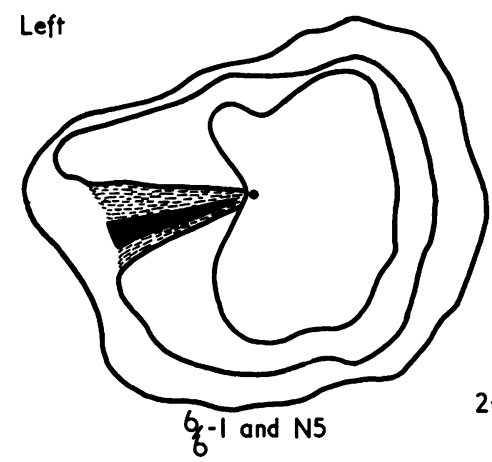

$2-5-63$

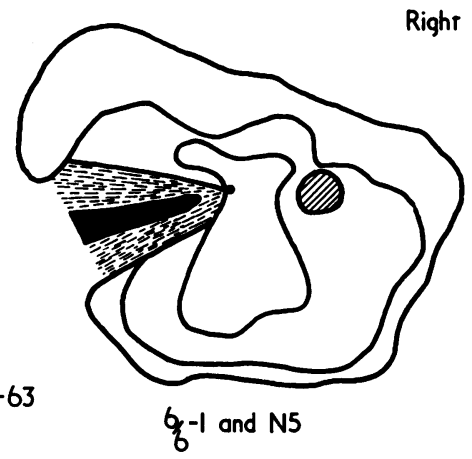

Fig. 2 Central 흠 visual fields one week $\overline{\frac{\rho}{T}}$ after presumed cerebro - vascular o accident.

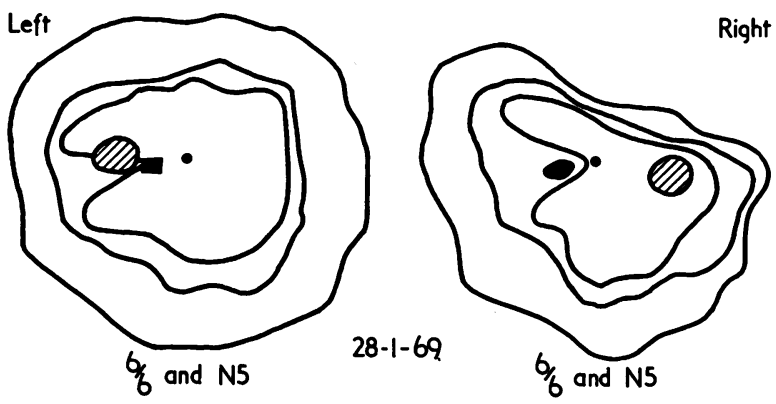

FIG. 3 Central visual fields 6 years after presumed cerebro-vascular accident

\section{Summary}

A case is described of non-traumatic hemianopia showing the picture elicited by Spalding (1952) in four patients who had sustained gunshot wounds involving the whole horizontal thickness of the intermediate part of the optic radiation in its anterior part.

The lesion in the present patient has been attributed to a vascular accident. Reviewo after 6 years shows an improvement in the visual fields with a decrease in density of the triangular sector defects and residual hemianopic scotomata at their apices.

The patient leads a normal life but suffers from mild temporal lobe seizures.

I am indebted to the surgeons of the Institute of Neurological Sciences, Glasgow, through whom the opportunity came to make these observations.

\section{References}

CUSHING, H. (1922) Brain, 44, 34I

HOLMES, G. (1918) Brit. F. Ophthal., 2, 353

MEYer, A. (1907) Trans. Ass. Amer. Physcns, 22, 7

polyak, s. (1934) "Localization of Function in the Gerebral Cortex", Res. Publ. Ass. nerv. ment $\stackrel{\mathscr{C}}{?}$

Dis., 13, 535

scotr, G. I. (1957) “Traquair's Clinical Perimetry", 7th ed., pp. 283-285. Kimpton, London spalding, J. M. K. (1952) J. Neurol. Neurosurg. Psychiat., 15, 99 